Target Journal: Neurology

\title{
A Randomized, Placebo-Controlled Phase 2 Trial of Laquinimod in Primary Progressive Multiple Sclerosis
}

Gavin Giovannoni, MBBCh, PhD; Volker Knappertz, MD; Joshua R. Steinerman, MD; Aaron P. Tansy, MD; Thomas Li, PhD; Stephen Krieger, MD; Antonio Uccelli, MD; Bernard M.J. Uitdehaag, MD; Xavier Montalban, MD; Hans-Peter Hartung, MD; Maria Pia Sormani, PhD; Bruce A.C. Cree, MD, PhD, MAS; Fred Lublin, MD; Frederik Barkhof, MD

\section{Affiliations}

From Queen Mary University of London, Blizard Institute, Barts and The London School of Medicine and Dentistry, London, UK (G.G.); Teva Pharmaceuticals R\&D, Teva Pharmaceutical Industries, Great Valley, Pennsylvania, USA and Department of Neurology, Medical Faculty, Heinrich-Heine Universität Düsseldorf, Düsseldorf, Germany (V.K.); Teva Pharmaceutical Industries, Malvern, Pennsylvania, USA (J. S.); Teva Pharmaceutical Industries, Malvern, Pennsylvania, USA (A. T.); Teva Pharmaceutical Industries, Great Valley, Pennsylvania, USA (T. L.); Corinne Goldsmith Dickinson Center for Multiple Sclerosis, Icahn School of Medicine at Mount Sinai, New York, NY, USA (S.K.); Department of Neuroscience, Rehabilitation, Ophthalmology, Genetics, Maternal and Child Health and Center of Excellence for Biomedical Research, University of Genoa, and Ospedale Policlinico San MartinoIRCCS, Genoa, Italy (A.U.); Amsterdam UMC, Vrije Universiteit Amsterdam, Department of Neurology, MS Center Amsterdam, Amsterdam, The Netherlands (B.M.J.U.); Division of Neurology, University of Toronto/MS Centre St Michael's Hospital, Toronto, Canada (X.M.); Neurology-Neuroimmunology Department \& 
Neurorehabilitation Unit, Multiple Sclerosis Centre of Catalonia, Barcelona, Spain (X.M.); Department of Neurology, Hospital Universitari de la Vall d'Hebron, Barcelona, Spain (X.M.); Department of Neurology, Medical Faculty, Heinrich-Heine University of Düsseldorf, Düsseldorf, Germany (H.H.); Department of Health Sciences, University of Genoa, Genoa, Italy (M. P. S.); Weill Institute for Neurosciences, Department of Neurology, University of California San Francisco, San Francisco, CA, USA (B.A.C.C.); Saunders Family Professor of Neurology, Icahn School of Medicine at Mount Sinai, New York, NY, USA (F.L.); Radiology \& Nuclear Medicine, VU University Medical Center, Amsterdam, The Netherlands, and UCL Institutes of Neurology and Healthcare Engineering, London, UK (F.B.)

\section{Corresponding Author}

Gavin Giovannoni

4 Newark St, London, E1 2AT, UK

Tel: +44 (0)20 7882 8954;

Email: g.giovannoni@qmul.ac.uk

\section{Supplemental Data}

Tables e-1 and e-2 and Figures e-1 and e-2 will be in the online version only.

\section{Statistical Analysis}

Thomas Li performed the statistical analysis and is affiliated with Teva Pharmaceutical Industries Ltd.

\section{Study Funding}


This study (NCT02284568) was funded by Teva Pharmaceutical Industries Ltd., Netanya, Israel.

Search Terms: Class 1 evidence [321], clinical trials randomized controlled [20], multiple sclerosis [41], primary progressive multiple sclerosis, laquinimod

Title character count: 90 with spaces; Abstract: 250 words; Text: 3356 words Number of tables: 5; Number of figures: 2; Number of references: 26

\section{Funding and Disclosures}

F.B. is supported by the NIHR Biomedical Research Centre at UCLH.

S.K. reports consulting or advisory work with Biogen, EMD Serono, Genentech, Genzyme, Mallinckrodt, MedDay, Novartis, Teva, and TG Therapeutics, and nonpromotional speaking with Biogen and Novartis.

B.M.J.U. has received consultancy fees and/or research support from Biogen Idec, Sanofi Genzyme, Merck Serono, Novartis, Roche, and Teva.

B.A.C.C. has received consultancy fees from AbbVie, Akili, Alexion, Biogen, EMD Serono, GeNeuro, Novartis, Sanofi Genzyme and TG Therapeutics.

H.P.H. has received fees for consulting, serving on steering and data monitoring committees and speaking from Bayer Healthcare, Biogen, Celgene Receptos, GeNeuro, MedDay, Merck, Novartis, Roche, Sanofi Genzyme, Teva, TG Therapeutics.

V.K., J.S., A.T., T.L., are employees of Teva Pharmaceutical Industries Ltd. 


\section{ABSTRACT}

Objective: To evaluate efficacy, safety, and tolerability of laquinimod in patients with primary progressive multiple sclerosis (PPMS).

Methods: In the randomized, double-blind, placebo-controlled, phase 2 study ARPEGGIO (A Randomized Placebo-controlled trial Evaluating laquinimod in PPMS, Gauging Gradations In MRI and clinical Outcomes), eligible PPMS patients were randomized $1: 1: 1$ to receive once-daily oral laquinimod $0.6 \mathrm{mg}$ or $1.5 \mathrm{mg}$ or matching placebo. Percentage brain volume change (PBVC; primary endpoint) from baseline to week 48 was assessed by MRI. Secondary and exploratory endpoints included clinical and MRI measures. Efficacy endpoints were evaluated using a predefined, hierarchical statistical testing procedure. Safety was monitored throughout the study. The laquinimod $1.5 \mathrm{mg}$ dose arm was discontinued on January 1, 2016 due to findings of cardiovascular events.

Results: 374 patients were randomized to laquinimod $0.6 \mathrm{mg}(\mathrm{n}=139)$ or $1.5 \mathrm{mg}(\mathrm{n}$ $=95)$ or placebo $(n=140)$. ARPEGGIO did not meet the primary endpoint of significant treatment effect with laquinimod $0.6 \mathrm{mg}$ versus placebo on PBVC from baseline to week 48 (adjusted mean difference $=0.016 \%, p=0.903)$. Laquinimod $0.6 \mathrm{mg}$ reduced the number of new T2 brain lesions at week 48 (risk ratio $=0.4 ; 95 \%$ confidence interval, $0.26-0.69 ; p=0.001)$. Incidence of adverse events was higher among patients treated with laquinimod $0.6 \mathrm{mg}(83 \%)$ versus laquinimod $1.5 \mathrm{mg}$ (66\%) and placebo (78\%).

Conclusions: Laquinimod $0.6 \mathrm{mg}$ did not demonstrate a statistically significant effect on brain volume loss in PPMS at week 48. 
Classification of Evidence: This study provides Class I evidence that, although well tolerated, laquinimod $0.6 \mathrm{mg}$ did not demonstrate a significant treatment effect on PBVC in patients with PPMS.

Clinical trial registration number: This trial was registered with ClinicalTrials.gov (NCT02284568).

\section{GLOSSARY}

9HPT = 9-Hole Peg Test; AE = adverse event; ALLEGRO = Assessment of oraL Laquinimod in PrEventing ProGRession in multiple SclerOsis; ARPEGGIO = A Randomized Placebo-controlled trial Evaluating laquinimod in PPMS, Gauging Gradations In MRI and clinical Outcomes; BICAMS = Brief International Cognitive Assessment for MS; BRAVO = Benefit Risk Assessment of aVonex and laquinimOd; BVMT = Brief Visuospatial Memory Test; $\mathbf{C l}=$ confidence interval; CDP $=$ confirmed disability progression; $\mathbf{C V L T}=$ California Verbal Learning Test; $\mathbf{D M C}=$ data monitoring committee; $\mathbf{D M T}=$ disease-modifying treatment; $\mathbf{E C G}=$ electrocardiograms; EDSS = Expanded Disability Status Scale; ET = early termination; FSS = Functional System Score; GdE = gadolinium-enhancing; ITT = intention-to-treat; ITTOn, on-treatment ITT; LCVA = low-contrast visual acuity; MRI = magnetic resonance imaging; $\mathbf{M S}=$ multiple sclerosis; $\mathbf{M S W S - 1 2}=12$-ltem Multiple Sclerosis Walking Scale; $\mathbf{M T R}=$ magnetization transfer ratio; $\mathbf{P B V C}=$ percent brain volume change; PPMS = primary progressive multiple sclerosis; PY, patient-years; RRMS = relapsing-remitting multiple sclerosis; SAE = serious adverse event; SDMT $=$ Symbol Digit Modalities Test; SIENA = Structural Image Evaluation, using Normalisation, of Atrophy; SE = standard error; T25FW = time 25-foot walk. 
6 (Giovannoni G et al) 


\section{INTRODUCTION}

Although relapsing-remitting multiple sclerosis (RRMS) has benefitted from advances in therapies, few are available for people with primary progressive multiple sclerosis (PPMS). ${ }^{1,2}$ This difference is largely due to differing underlying disease pathways in the central nervous system. ${ }^{3}$ As a result, focus has shifted to development of novel therapies for PPMS that offer a broadened scope of target pathogenic processes. ${ }^{4}$

Laquinimod is a small molecule oral immunomodulator. ${ }^{5,6}$ Preclinical studies indicated that the principal mechanism of action is the selective activation of the aryl hydrocarbon receptor, expressed mainly on cells of the adaptive immune response, ${ }^{7}$ and demonstrated that laquinimod reduces microglial and astrocytic reactivity and increases the level of brain-derived neurotrophic factor. ${ }^{8-10}$ Two phase 3 studies in RRMS completed before the ARPEGGIO (A Randomized Placebo-controlled trial Evaluating laquinimod in PPMS, Gauging Gradations In MRI and clinical Outcomes) study showed treatment effects of oral laquinimod $0.6 \mathrm{mg}$ on clinical disability progression and brain volume loss, which were larger than expected based on the relapse reduction. ${ }^{11,12}$ In the ALLEGRO (Assessment of oraL Laquinimod in prEventing proGRession in multiple sclerOsis) RRMS study, laquinimod reduced white matter and grey matter atrophy $(p=0.004$ each) and thalamic atrophy from baseline to month $12(p=0.005) \cdot{ }^{13}$ These results in patients with RRMS suggest that laquinimod $0.6 \mathrm{mg}$ has an anti-inflammatory and/or neuroprotective effect in the central nervous sytem and could have similar benefits for the reduction of atrophy in patients with PPMS. 
ARPEGGIO was a phase 2, proof-of-concept, multicenter, randomized, double-blind, parallel-group, placebo-controlled study to evaluate efficacy, safety and tolerability of daily oral laquinimod $0.6 \mathrm{mg}$ and $1.5 \mathrm{mg}$ in patients with PPMS.

\section{METHODS}

\section{Standard protocol approvals, registrations, and patient consent}

The ARPEGGIO study was approved by independent ethics committees or institutional review boards according to national or local regulations. This study was conducted in full accordance with the International Council for Harmonisation of Technical Requirements for Pharmaceuticals for Human Use (ICH) Good Clinical Practice Consolidated Guideline (E6) and any applicable national and local laws and regulations. To ensure patients' welfare, an independent data monitoring committee (DMC) reviewed trial progress and safety data, periodically and on an ad hoc basis. All patients provided written informed consent before any study procedures or assessments were performed. This trial was registered with ClinicalTrials.gov (NCT02284568).

\section{Patient recruitment and eligibility}

Patients were randomized $(n=374)$ from January 2015 to April 2016 at 85 sites in 10 countries.

Key inclusion criteria were as follows: aged 25-55 years, inclusive; a confirmed and documented diagnosis of PPMS as defined by the 2010 Revised McDonald criteria; a score of 3.0-6.5, inclusive, on the Expanded Disability Status Scale (EDSS) ${ }^{14}$ at 
both screening and baseline visits; baseline MRI showing lesions consistent with PPMS in the brain and/or spinal cord; documented worsening of clinical disability in the 2 years prior to screening; and a Functional System Score (FSS) $\geq 2$ for the pyramidal system or gait impairment due to lower limb dysfunction. A capped randomization procedure ensured that $\leq 20 \%$ of all enrolled patients had a baseline EDSS score of 6.0 and 6.5. Among the 374 enrolled patients enrolled, 35 patients (9.4\%) had a baseline EDSS score of 6.0 or 6.5 .

Key exclusion criteria were as follows: clinical history of any multiple sclerosis (MS) exacerbations or relapses, including any episodes of neuromyelitis optica; any progressive neurological disorder other than PPMS; MRI evidence of cervical cord compression; history of vitamin B12 deficiency; positive human T-lymphotropic virus type I and II (HTLV-I/II serology); use of immunosuppressive or cytotoxic agents, including azathioprine and cyclophosphamide, within 48 weeks prior to baseline evaluation or use of experimental or investigational drugs and/or participation in drug clinical studies within 24 weeks prior to randomization; and previous treatment with fingolimod, dimethyl fumarate, glatiramer acetate, or interferon- $\beta$ (either 1a or $1 b$ ); and any previous use of laquinimod.

\section{Study design}

The ARPEGGIO trial was a randomized, double-blind, parallel-group, placebocontrolled study with a screening period up to 6 weeks and two study phases, part A (core study) and part B (data analysis). Eligible patients were randomized in a 1:1:1 ratio to receive oral laquinimod $0.6 \mathrm{mg}$ or $1.5 \mathrm{mg}$ or matching placebo once daily. The $1.5 \mathrm{mg}$ arm was included as the maximal dose based on two studies that 
showed a laquinimod dose response up to $0.6 \mathrm{mg}$ (based on MRI parameters) and a third multiple ascending dose study of up to $2.7 \mathrm{mg}$ that showed no dose-limiting adverse events (AEs) or laboratory findings. Randomization was performed centrally using an independent interactive Web-based or voice response system. Patients, investigators, the sponsor, and designated personnel were blinded to treatment assignments. Once the last ongoing patient completed the week 48 visit, the sponsor declared the end of part A and began performing study analyses (part B). During part B, patients continued their randomly assigned blinded treatments, with visits every 12 weeks until the completion visit (Figure e-1). An optional extension study was planned for consideration for patients who completed parts A and B of the trial; however, the extension study was not conducted, and the study was completed at the end of part B.

The laquinimod $1.5 \mathrm{mg}$ dose arm was discontinued as of January 1, $2016 \mathrm{in}$ agreement with DMC recommendation, owing to findings of an imbalance in serious cardiovascular events at laquinimod doses above $0.6 \mathrm{mg}$ once daily in ARPEGGIO and another concurrent clinical study in relapsing MS (CONCERTO). All participating sites were notified of these findings and dose discontinuation, and all study participants were asked for reconsent to continue with study participation. Patients originally randomized to laquinimod $0.6 \mathrm{mg}$ retained their treatment assignment. Patients exposed to laquinimod $1.5 \mathrm{mg}$ were encouraged to continue follow-up in the study after discontinuation of study drug. 


\section{Study procedures}

Patients underwent the following scheduled visits: screening (-6 weeks), baseline (week 0), weeks $4,8,12,24,36,48$, and every 12 weeks thereafter until study completion or early termination (ET). Blood samples were collected from all patients at weeks $4,8,12,24$, and 48 for plasma concentration measurements of laquinimod. All patients underwent brain and cervical spinal cord MRI scans, including gadolinium at baseline and without gadolinium at weeks 24 and 48 within 14 days of the scheduled clinical visit. MRI scans included 3D T1-weighted isotropic images of the brain and spinal cord and were collected centrally at the VUmc in Amsterdam. Upon successful certification of sites, all scans were quality checked for pulsesequence parameters and movement artifacts that would interfere with the relevant outcome and read in a fully blinded fashion by trained operators. Percent brain volume change (PBVC) was measured using Structural Image Evaluation, using Normalisation, of Atrophy (SIENA) software, and cord area change was determined using the mean upper cervical cord area (MUCCA) software. ${ }^{15}$ T2-hyperintense and T1-hypointense lesion volumes were determined from 3-mm slices using local thresholding with Medical Image Processing, Analysis, and Visualization (MIPAV) software, ${ }^{16}$ and new lesions were counted. Regional atrophy measures, and magnetization transfer ratios (MTRs) were determined using automated tissue-type segmentation for cortical grey matter and deep grey matter. ${ }^{17,} 18$ Cervical cord lesions were counted on sagittal proton-density images. EDSS and FSS were performed every 12 weeks until completion or ET visit (if applicable). Timed 25-Foot Walk (T25FW), 9-Hole Peg Test (9HPT), and Symbol Digit Modalities Test (SDMT) assessments were performed every 12 weeks until completion or ET visit (if 
applicable). Brief International Cognitive Assessment for MS (BICAMS), including SDMT, was evaluated at baseline and every 48 weeks thereafter. Modified Rankin Score was evaluated at week 72. Low-contrast visual acuity (LCVA) was assessed at baseline and every 24 weeks until completion or ET (if applicable). The 12-Item Multiple Sclerosis Walking Scale (MSWS-12) was used to assess an individual's walking ability at baseline and every 12 weeks until completion or ET (if applicable).

EDSS and FSS assessments were performed by an examining neurologist who remained unaware of the patient's safety status and was strictly instructed not to discuss safety issues with the treating physician, to assure an accurate and objective evaluation.

\section{Study endpoints}

The primary endpoint of the study was brain atrophy, as defined by the PBVC from baseline to week 48 . For patients with early treatment discontinuation or completion visit prior to week 48 , the last MRI scan was included in the analysis if it was performed at least 36 weeks on study.

Secondary endpoints were time to confirmed disability progression (CDP). CDP was measured by two types of events for each individual; note that progression could not be confirmed during a relapse. One event was an increase from baseline in EDSS score $[\geq 1$ EDSS point from baseline if EDSS at entry was $\leq 5.0$ or $\geq 0.5$ point from baseline if EDSS at entry was $\geq 5.5]$. The second was an increase of $\geq 20 \%$ from baseline in the T25FW score. Both measures of CDP were confirmed after at least 
12 weeks. There were two additional secondary efficacy endpoints: change from baseline to week 48 in the T25FW score and the number of new T2 brain lesions at week 48.

Exploratory endpoints included change from baseline to week 48 in the BICAMS score and time to CDP confirmed after at least 12 and 24 weeks as measured by at least 1 of 4 types of events for each individual (progression could not be confirmed during a relapse): an increase from baseline in EDSS score ( $\geq 1$ point from baseline EDSS if EDSS at entry was $\leq 5.0$ or $\geq 0.5$ point if EDSS at entry was $\geq 5.5$ ); an increase of $\geq 20 \%$ from baseline in the $\mathrm{T} 25 \mathrm{FW}$ score; an increase of $\geq 30 \%$ from baseline in the 9HPT score; or a decrease of $\geq 20 \%$ from baseline in the SDMT score. MRI parameters included new T1-hypointense lesions, changes in T1hypointense lesion volume, and changes in T2 lesion volume; atrophy parameters including thalamic, cortical, white matter, and cervical cord atrophy; number of cervical cord T2 lesions; and normal-appearing brain tissue average MTR.

Safety endpoints included assessment of AEs throughout the study and vital signs, electrocardiograms (ECG), and clinical laboratory parameters and concomitant medication usage. ECG findings assessed as 'abnormal, clinically significant' were evaluated by the DMC cardiologist. Assessment of tolerability included evaluation of the proportion of patients who prematurely discontinued treatment, including those with early treatment discontinuation due to AEs.

\section{Statistical analysis}

The study was planned to enroll 126 patients per treatment group with a two-sided alpha level of $5 \%$ to show a 0.3 treatment difference (delta) in PBVC over 48 weeks 
and standard deviation of 0.8 in order to reach power of $80 \%$. The dropout rate for power calculations was assumed at $10 \%$.

The primary efficacy variable, PBVC, and the ranked value of change from baseline in T25FW were analyzed using a baseline-adjusted repeated measures model that included treatment group, week, treatment by week interaction, normalized brain volume at baseline, natural logarithm of T2 lesion volume at baseline and country/geographical region as covariates. The time-to-event efficacy variables, CDP measured in EDSS, CDP measured in EDSS or T25FW, CDP measured in EDSS, T25FW, 9HPT, or SDMT, were analyzed using a baseline-adjusted Cox proportional hazards regression model that included treatment group, categorical EDSS at baseline ( $\leq 4.5$ or $>4.5$ ), age at baseline, natural logarithm of T2 lesion volume at baseline, and country as covariates. The time-to-event results are presented in Kaplan-Meier plots.

Number of new T2 lesions was analyzed using a negative binomial regression model with treatment group, natural logarithm of T2 lesion volume at baseline, age at baseline, and country as fixed effects.

The overall significance level for this study was $5 \%$ using two-tailed tests and/or twosided confidence intervals (Cls) with 95\% confidence level. To protect from type-1error inflation, the secondary endpoints were interpreted inferentially only if a statistically significant treatment effect was detected in the primary analysis. 
All of the analyses were performed using SAS software (version 9.3). Efficacy analyses were performed on the intention-to-treat (ITT) population, the modified ITT1 population (mITT1), or the modified ITT2 population (mITT2). The ITT population included all randomized patients. The mITT1 population was defined as all randomized patients (ITT population) with at least 1 post-baseline PBVC assessment. The mITT2 population consisted of all randomized patients with at least 1 post-baseline assessment (EDSS, SDMT, California Verbal Learning Test, Brief Visuospatial Memory Test, T25FW, 9HPT, LCVA and/or MSWS-12). The safety analyses were performed on all randomized patients who received $\geq 1$ dose of study drug.

\section{Classification of evidence}

This interventional study provides class I evidence that laquinimod $0.6 \mathrm{mg}$ did not demonstrate a significant treatment effect on PBVC, nor on any disability-related outcome.

\section{Data availability statement}

All data on individual participants that underlie the results reported in the article can be made available, after deidentification. Data can be made available after publication of this article, up to 36 months after publication. The data can be shared 
with investigators whose proposed use of the data has been approved by an independent review committee, to achieve the aims in the approved proposal.

\section{RESULTS}

\section{Patient disposition and baseline characteristics}

A total of 374 patients underwent randomization (ITT population) to one of three study groups (Figure e-2). Baseline demographics and disease characteristics were similar across groups; however, the mean values in time since diagnosis for active arms were numerically larger than that for placebo (Table 1). Most (84\%) of the study population were from European countries, with Spain (16\%), Ukraine (14\%), Germany (12\%), and Russia (11\%) being the leading recruiters and most patients (96\%) being White (non-Hispanic or Latino). Of the 374 patients enrolled in the study, $84(24 \%)$ had previously used disease-modifying treatments (Table e-2).

Patient disposition and reasons for treatment discontinuation can be found in Figure e-2. Of the 279 patients originally randomized to either laquinimod $0.6 \mathrm{mg}$ or placebo, 220 (laquinimod $0.6 \mathrm{mg}, \mathrm{n}=107$ [77\%]; placebo, $\mathrm{n}=113$ [81\%]) completed the week $48 \mathrm{MRI}$ on treatment, with 202 (laquinimod $0.6 \mathrm{mg}, \mathrm{n}=93$ [67\%]; placebo, $\mathrm{n}=109[78 \%])$ still receiving the study drug at the end of the trial. A total of 15 
patients (laquinimod $1.5 \mathrm{mg}, \mathrm{n}=6$; laquinimod $0.6 \mathrm{mg}, \mathrm{n}=5$; placebo, $\mathrm{n}=4$ ) underwent MRI scans during an ET visit.

\section{PBVC}

A prespecified sensitivity analysis including treatment group, week, treatment group by week interaction, normalized brain volume at baseline, natural logarithm of T2 lesion volume at baseline, country, gender, age at baseline, time from first MS symptom (years), time from PPMS diagnosis (years), the number of gadolinium enhancing ( $\mathrm{GdE})$ at baseline, flag of PPMS diagnosis with positive cerebrospinal fluid (CSF), and category of baseline EDSS as fixed effects was done for the primary efficacy endpoint, and the results were similar to the those of the predefined primary analysis.

Efficacy endpoints for laquinimod versus placebo are shown in Figure 1 and Table

2. Patients receiving laquinimod $0.6 \mathrm{mg}$ did not differ significantly in PBVC from baseline to 48 weeks compared with patients receiving placebo (adjusted mean, $-0.454 \%$ vs $-0.438 \%$; adjusted mean difference, $0.016 \% ; 95 \% \mathrm{Cl},-0.239 \%$ to $0.271 \% ; p=0.903$ ) (Table 2 and Figure 1). As a result of the failure in the statistical hierarchical testing, all of the $p$ values for the subsequent efficacy endpoints were considered to be non-inferential.

\section{Disease progression}

The Kaplan-Meier proportion estimates of patients with 12-week CDP as measured by EDSS (secondary endpoint) over the study period were similar between the 
laquinimod $0.6 \mathrm{mg}$ group and the placebo group (17\% vs $23 \%$; hazard ratio, 0.80 ; $95 \% \mathrm{Cl}, 0.48-1.37 ; p=0.426$ ) (Figure 2 and Table 2). Treatment differences for the other secondary clinical endpoints of 12-week confirmed disease progression (EDSS or T25FW) or change in T25FW score (seconds) from baseline to week 48 (Table 2) were not observed. No treatment difference was seen in exploratory clinical analyses, including that of 12-week CDP as defined by worsening of EDSS, T25FW, 9HPT, or SDMT (exploratory endpoint) (Table e-1).

\section{MRI-related endpoints}

Patients on laquinimod $0.6 \mathrm{mg}$ showed reduced number of new T2 brain lesions at week $48 \mathrm{MRI}$ (secondary endpoint) by $60 \%$ versus the placebo group (estimate 0.7 vs 1.6 ; risk ratio $0.4 ; 95 \% \mathrm{Cl}, 0.26-0.69 ; p=0.001$ ) (Table 2). The number of new T1 hypointense lesions at week 48 was lower with laquinimod $0.6 \mathrm{mg}$, but the change was not statistically significant versus placebo (estimate 0.4 vs 0.7 ; risk ratio 0.5 ; $95 \% \mathrm{Cl}, 0.27-1.01 ; p=0.055)$. Additionally, patients in the laquinimod group showed reduced volume change in both T1-hypointense and T2 lesions at the week $48 \mathrm{MRI}$ (exploratory endpoints) (Table 2). No treatment differences were seen in (regional) brain or cord atrophy rates, MTR-related endpoints, or number of cord T2 lesions (Table 2).

\section{Safety and tolerability}

Safety was evaluated in the safety population set, with a cumulative exposure to study drug of 203.3 patient-years (PY) for the laquinimod 0.6 mg group, 28.7 PY for the laquinimod 1.5 mg group, and 225.9 PY for the placebo group (Table 3). Two 
fatalities were reported in the study, one death was considered by the investigator as possibly related to the drug and occurred in the laquinimod $1.5 \mathrm{mg}$ treatment group (myocardial ischemia, fatal, 35 days after drug discontinuation), and the other death occurred during the screening phase of the trial and was considered by the investigator as not related to study drug (accidental death). A total of 115 patients $(83 \%)$ in the laquinimod $0.6 \mathrm{mg}$ group and 63 patients (66\%) in the laquinimod 1.5 mg group reported an AE, compared with 109 (78\%) patients in the placebo group (Table 3). A higher incidence of AEs leading to discontinuation was observed in patients in the laquinimod $0.6 \mathrm{mg}$ group compared with patients in the placebo group. AEs that occurred in at least $5 \%$ of patients in any group are listed in Table 4 .

Serious adverse events are reported in Table 5. Nineteen patients across all arms had at least one SAE. An imbalance in serious cardiovascular events in the laquinimod $1.5 \mathrm{mg}$ arm of this study and in the laquinimod $1.2 \mathrm{mg}$ arm of the concurrent RRMS study (CONCERTO; 6 cases of serious cardiovascular events with laquinimod $1.2 \mathrm{mg}$ versus none with laquinimod $0.6 \mathrm{mg}$ or placebo) led the DMC to recommend stopping all treatment arms above $0.6 \mathrm{mg}$ on January 1, 2016. In the ARPEGGIO study, a 50 -year old white female patient in the laquinimod $1.5 \mathrm{mg}$ group experienced a mild $\mathrm{AE}$ of unstable angina, which was assessed by the investigator to be serious. Treatment was subsequently discontinued, and the unstable angina resolved by day 15 . The investigator considered the AE to be treatment related, and the patient discontinued the study on day 49. A 50-year old male patient in the laquinimod $1.5 \mathrm{mg}$ group died due to severe AEs of arteriosclerosis of the coronary artery and myocardial ischemia, both of which were assessed by the investigator and 
found to be serious. These events occurred 35 days after the last administration of the study drug and were considered to be treatment related.

\section{DISCUSSION}

In the current ARPEGGIO study, the laquinimod $1.5 \mathrm{mg}$ arm was discontinued early following the DMC's review of the cardiovascular safety data for both this trial and the concurrent RRMS study (CONCERTO). In this study of patients with PPMS, laquinimod $0.6 \mathrm{mg}$ failed to demonstrate a statistically significant effect on change from baseline in PBVC. Of the secondary and exploratory endpoints evaluated, laquinimod $0.6 \mathrm{mg}$ had a significant effect on the number of new focal lesions $(60 \%$ reduction for T2) and their associated lesion volume.

The lack of significant change in PBVC following treatment with laquinimod $0.6 \mathrm{mg}$ in patients with PPMS is in contrast with three phase 3 placebo-controlled studies of laquinimod $0.6 \mathrm{mg}$ in patients with RRMS (ALLEGRO, BRAVO, and CONCERTO). In the BRAVO study, laquinimod $0.6 \mathrm{mg}$ significantly reduced PBVC by $28 \%$ ( $p<$ 0.001 vs placebo) over 12 months; ${ }^{12}$ in the CONCERTO study, laquinimod $0.6 \mathrm{mg}$ reduced PBVC by $40 \%$ from baseline to month 15 ( $p<0.0001$ vs placebo). ${ }^{19}$ In a single-center frequent MRI sub-study of ALLEGRO, laquinimod reduced white matter and grey matter atrophy from baseline to month $12(p=0.004)$ and white matter at 24 months $(p=0.035)$ and showed a trend toward less grey matter atrophy at 24 months $(p=0.078)$. Laquinimod also slowed thalamic atrophy at 12 months $(p=$ $0.005)$ and 24 months $(p=0.003) .{ }^{13}$ 
Phase 3 studies of fingolimod, an oral sphingosine 1-phosphate receptor modulator, demonstrated a similar disconnect in PBVC as an endpoint, with fingolimod treatment showing a significant change in brain volume in patients with RRMS (FREEDOMS) but not in those with PPMS (INFORMS). ${ }^{20,21}$ In contrast, a phase 2 trial of ibudilast in patients with progressive MS (SPRINT-MS) showed an effect on the rate of change of brain volume compared with placebo $(p=0.04)$ over 96 weeks. ${ }^{22}$ The exact reason for these differences is not fully understood; however, it has been suggested that different pathophysiological mechanisms drive PBVC in PPMS and RRMS, with neurodegenerative processes having a more prominent role in PPMS. ${ }^{20}$

Notable differences in MRI findings in the brain between PPMS and RRMS and in the biological disease characteristics of PPMS compared with RRMS may explain the negative results we observed using this endpoint. ${ }^{23}$ In PPMS, neurological disability gradually worsens from symptom onset over months or years, whereas RRMS is characterized by episodes of acute neurological deterioration (relapses) followed by partial or complete recovery (remission). ${ }^{23}$ Additionally, in PPMS, inflammation is less prominent than in RRMS. ${ }^{20}$

The nonlinear effects on brain volume in the active arm (Figure 1) may suggest that laquinimod is crossing the blood-brain barrier and influencing cellular volume, particularly in glial cells, i.e., astrocytes and microglia, as has been demonstrated in preclinical studies. ${ }^{7,8}$ Conversely, high-dose biotin, which has been suggested in early explorative studies to improve clinical outcomes in PPMS, can accelerate brain volume loss, consistent with a pseudo-atrophy phenomenon linked to a decrease in 
brain water volume, perhaps triggered by increased energy production. ${ }^{24,25}$ These results indicate that short-term brain volume changes represent complex biological changes and thus may not be a reliable surrogate for neuroprotection in MS trials in the short term, though examples exist of more linear behavior. ${ }^{26}$

The effect of laquinimod on the number of focal lesions and associated lesion volume in this study was numerically larger than that in previously reported studies of laquinimod. ${ }^{11,12}$ Notably, laquinimod treatment in this study reduced the number of T2 lesions by $60 \%$. In contrast, the ALLEGRO study reported a reduction of $30 \%$ in the mean number of new or enlarged T2-weighted lesions by $30 \%(p<0.001$ vs placebo)..${ }^{11}$ In the BRAVO study, laquinimod reduced the total number of T2 lesions by $19 \%(p=0.037$ vs placebo $) .^{12}$

The population included in ARPEGGIO was comparable with and representative of those seen in previous PPMS trials, with a relatively short disease duration (8 years) and some evidence of ongoing subclinical inflammatory activity (mean $0.3 \mathrm{GdE}$ lesions) (Table e-3). ${ }^{20,22,27-29}$ This suggests that the ALLEGRO study succeeded in recruiting a characteristic progressing population.

This study lost some statistical power due to a higher than expected dropout rate in each treatment arm. The dropout rates in this 48 -week study were $32 \%$ in the laquinimod $0.6 \mathrm{mg}$ arm and $22 \%$ in placebo arm. In comparison, the dropout rates for the 1-year ALLEGRO (laquinimod $0.6 \mathrm{mg}$ : 12.0\%, placebo: 15.2\%) and the 24month BRAVO (18.7\% and $20.2 \%$ for laquinimod $0.6 \mathrm{mg}$ and placebo, respectively) were numerically lower despite the longer study duration. ${ }^{11,12}$ It is likely that a lower 
dropout rate may not have a significant impact on the results, considering that no trend in PBVC was observed with laquinimod $0.6 \mathrm{mg}$. Additionally, the rate of PBVC approached $0.5 \%$ per year, which is within the ranges reported in previous PPMS trials of fingolimod (INFORMS), ${ }^{20}$ ocrelizumab (ORATORIO), ${ }^{27}$ rituximab (OLYMPUS), ${ }^{29}$ and ibudilast (SPRINT-MS). ${ }^{22}$ For example, in a phase 3 PPMS trial evaluating the efficacy of fingolimod (INFORMS), the change in brain volume over a 3-year span was $1.5 \%$ in both the fingolimod and the placebo arms. ${ }^{20}$ Although data comparison across studies may be confounded by differences in collection and quality of imaging data, these consistencies suggest that the assumptions underlying the power calculations were valid.

In summary, the ARPEGGIO study failed to provide proof-of-concept evidence for a neuroprotective effect of laquinimod in PPMS. This indicates that the reduction in inflammatory-mediated lesions observed with laquinimod does not translate to slowing of brain volume loss in PPMS patients.

\section{Acknowledgements}

We thank Chameleon Communications International with funding from Teva Pharmaceuticals for editorial assistance in the preparation of this report. 


\section{Appendix 1}

\begin{tabular}{|c|c|c|c|}
\hline Name & Location & Role & Contribution \\
\hline $\begin{array}{l}\text { Gavin Giovannoni, } \\
\text { MBBCh, PhD }\end{array}$ & $\begin{array}{l}\text { Queen Mary University } \\
\text { of London, Blizard } \\
\text { Institute, Barts and The } \\
\text { London School of } \\
\text { Medicine and Dentistry, } \\
\text { London, UK }\end{array}$ & Corresponding Author & $\begin{array}{l}\text { Conceived and } \\
\text { designed the } \\
\text { analysis; } \\
\text { collected the data; } \\
\text { contributed data or } \\
\text { analysis tools; } \\
\text { performed the } \\
\text { analysis; } \\
\text { writing - original } \\
\text { draft preparation; } \\
\text { writing - critical } \\
\text { review and editing }\end{array}$ \\
\hline Volker Knappertz, MD & $\begin{array}{l}\text { Teva Pharmaceuticals } \\
\text { R\&D, Teva } \\
\text { Pharmaceutical } \\
\text { Industries, Great Valley, } \\
\text { Pennsylvania, USA; } \\
\text { Department of } \\
\text { Neurology, Medical } \\
\text { Faculty, Heinrich-Heine } \\
\text { Universität Düsseldorf, } \\
\text { Düsseldorf, Germany }\end{array}$ & Author & $\begin{array}{l}\text { Conceived and } \\
\text { designed the trial } \\
\text { and its analysis; } \\
\text { supervision of trial } \\
\text { conduct; } \\
\text { safety monitoring } \\
\text { and key decision } \\
\text { maker in } \\
\text { discontinuing high- } \\
\text { dose arm; } \\
\text { data interpretation } \\
\text { and contextual } \\
\text { discussion; } \\
\text { critical review, data } \\
\text { interpretation, } \\
\text { writing, and editing }\end{array}$ \\
\hline $\begin{array}{l}\text { Joshua R. Steinerman, } \\
\text { MD }\end{array}$ & $\begin{array}{l}\text { Teva Pharmaceutical } \\
\text { Industries, Malvern, PA, } \\
\text { USA }\end{array}$ & Author & $\begin{array}{l}\text { Conceived and } \\
\text { designed the } \\
\text { analysis; } \\
\text { collected the data; } \\
\text { writing - critical } \\
\text { review and editing }\end{array}$ \\
\hline Aaron P. Tansy, MD & $\begin{array}{l}\text { Teva Pharmaceutical } \\
\text { Industries, Malvern, PA, } \\
\text { USA }\end{array}$ & Author & $\begin{array}{l}\text { Collected the data; } \\
\text { writing - original } \\
\text { draft preparation; } \\
\text { writing - critical } \\
\text { review and editing }\end{array}$ \\
\hline Thomas Li, PhD & $\begin{array}{l}\text { Teva Pharmaceutical } \\
\text { Industries, Great Valley, } \\
\text { PA, USA }\end{array}$ & Author & $\begin{array}{l}\text { Performed the } \\
\text { analysis; } \\
\text { writing - critical } \\
\text { review and editing }\end{array}$ \\
\hline Stephen Krieger, MD & $\begin{array}{l}\text { Corinne Goldsmith } \\
\text { Dickinson Center for } \\
\text { Multiple Sclerosis, } \\
\text { Icahn School of } \\
\text { Medicine at Mount } \\
\text { Sinai, New York, NY, } \\
\text { USA }\end{array}$ & Author & $\begin{array}{l}\text { Conceived and } \\
\text { designed the } \\
\text { analysis; } \\
\text { writing - original } \\
\text { draft preparation; } \\
\text { writing - critical } \\
\text { review and editing }\end{array}$ \\
\hline
\end{tabular}




\begin{tabular}{|c|c|c|c|}
\hline Antonio Uccelli, MD & $\begin{array}{l}\text { Department of } \\
\text { Neuroscience, } \\
\text { Rehabilitation, } \\
\text { Ophthalmology, } \\
\text { Genetics, Maternal and } \\
\text { Child Health and Center } \\
\text { of Excellence for } \\
\text { Biomedical Research, } \\
\text { University of Genoa, } \\
\text { and Ospedale } \\
\text { Policlinico San Martino- } \\
\text { IRCCS, Genoa, Italy }\end{array}$ & Author & $\begin{array}{l}\text { Collected the data; } \\
\text { writing - critical } \\
\text { review and editing }\end{array}$ \\
\hline $\begin{array}{l}\text { Bernard M.J. } \\
\text { Uitdehaag, MD }\end{array}$ & $\begin{array}{l}\text { Amsterdam UMC, Vrije } \\
\text { Universiteit Amsterdam, } \\
\text { Department of } \\
\text { Neurology, MS Center } \\
\text { Amsterdam, } \\
\text { Amsterdam, The } \\
\text { Netherlands }\end{array}$ & Author & $\begin{array}{l}\text { Contribution to trial } \\
\text { design; } \\
\text { data interpretation } \\
\text { and contextual } \\
\text { discussion; } \\
\text { critical review and } \\
\text { editing of the } \\
\text { manuscript }\end{array}$ \\
\hline Xavier Montalban, MD & $\begin{array}{l}\text { Division of Neurology, } \\
\text { University of } \\
\text { Toronto/MS Centre St } \\
\text { Michael's Hospital, } \\
\text { Toronto, Canada; } \\
\text { Department of } \\
\text { Neurology, Hospital } \\
\text { Universitari de la Vall } \\
\text { d'Hebron, Barcelona, } \\
\text { Spain; Neurology- } \\
\text { Neuroimmunology } \\
\text { Department \& } \\
\text { Neurorehabilitation Unit, } \\
\text { Multiple Sclerosis } \\
\text { Centre of Catalonia, } \\
\text { Barcelona, Spain }\end{array}$ & Author & $\begin{array}{l}\text { Conceived and } \\
\text { designed the } \\
\text { analysis; } \\
\text { collected the data; } \\
\text { contributed data or } \\
\text { analysis tools; } \\
\text { performed the } \\
\text { analysis; } \\
\text { writing - original } \\
\text { draft preparation; } \\
\text { writing - critical } \\
\text { review and editing }\end{array}$ \\
\hline $\begin{array}{l}\text { Hans-Peter Hartung, } \\
\text { MD }\end{array}$ & $\begin{array}{l}\text { Department of } \\
\text { Neurology, Medical } \\
\text { Faculty, Heinrich-Heine } \\
\text { University of } \\
\text { Düsseldorf, Düsseldorf, } \\
\text { Germany }\end{array}$ & Author & $\begin{array}{l}\text { Conceived and } \\
\text { designed the } \\
\text { analysis; } \\
\text { collected the data; } \\
\text { contributed data or } \\
\text { analysis tools; } \\
\text { writing - original } \\
\text { draft preparation }\end{array}$ \\
\hline $\begin{array}{l}\text { Maria Pia Sormani, } \\
\text { PhD }\end{array}$ & $\begin{array}{l}\text { Department of Health } \\
\text { Sciences, University of } \\
\text { Genoa, Genoa, Italy }\end{array}$ & Author & $\begin{array}{l}\text { Conceived and } \\
\text { designed the } \\
\text { analysis; } \\
\text { writing - original } \\
\text { draft preparation; } \\
\text { writing - critical } \\
\text { review and editing }\end{array}$ \\
\hline $\begin{array}{l}\text { Bruce A.C. Cree, MD, } \\
\text { PhD, MAS }\end{array}$ & $\begin{array}{l}\text { Weill Institute for } \\
\text { Neurosciences, } \\
\text { Department of } \\
\text { Neurology, University of } \\
\text { California San }\end{array}$ & Author & $\begin{array}{l}\text { Conceived and } \\
\text { designed the } \\
\text { analysis; } \\
\text { collected the data; } \\
\text { writing - critical } \\
\text { review and editing }\end{array}$ \\
\hline
\end{tabular}




\begin{tabular}{|c|c|c|c|}
\hline & $\begin{array}{l}\text { Francisco, San } \\
\text { Francisco, CA, USA }\end{array}$ & & \\
\hline Fred Lublin, MD & $\begin{array}{l}\text { Saunders Family } \\
\text { Professor of Neurology, } \\
\text { Icahn School of } \\
\text { Medicine at Mount } \\
\text { Sinai, New York, NY, } \\
\text { USA }\end{array}$ & Author & $\begin{array}{l}\text { Contributed data or } \\
\text { analysis tools; } \\
\text { performed the } \\
\text { analysis; } \\
\text { writing - critical } \\
\text { review and editing }\end{array}$ \\
\hline Frederik Barkhof, MD & $\begin{array}{l}\text { Radiology \& Nuclear } \\
\text { Medicine, VU University } \\
\text { Medical Center, } \\
\text { Amsterdam, The } \\
\text { Netherlands, and UCL } \\
\text { Institutes of Neurology } \\
\text { and Healthcare } \\
\text { Engineering, London, } \\
\text { UK }\end{array}$ & Author & $\begin{array}{l}\text { Conceived and } \\
\text { designed the } \\
\text { analysis; } \\
\text { collected the data; } \\
\text { contributed data or } \\
\text { analysis tools; } \\
\text { performed the } \\
\text { analysis; } \\
\text { writing - original } \\
\text { draft preparation; } \\
\text { writing - critical } \\
\text { review and editing }\end{array}$ \\
\hline
\end{tabular}




\section{REFERENCES}

1. English C, Aloi JJ. New FDA-Approved Disease-Modifying Therapies for Multiple Sclerosis. Clin Ther 2015;37:691-715.

2. Ciotti JR, Cross AH. Disease-Modifying Treatment in Progressive Multiple Sclerosis. Curr Treat Options Neurol 2018;20:12.

3. Ratzer R, Sondergaard HB, Christensen JR, et al. Gene expression analysis of relapsing-remitting, primary progressive and secondary progressive multiple sclerosis. Mult Scler 2013;19:1841-1848.

4. Narayan RN, Forsthuber $\mathrm{T}$, Stuve $\mathrm{O}$. Emerging drugs for primary progressive multiple sclerosis. Expert Opin Emerg Drugs 2018;23:97-110.

5. Varrin-Doyer M, Zamvil SS, Schulze-Topphoff U. Laquinimod, an up-andcoming immunomodulatory agent for treatment of multiple sclerosis. Exp Neurol 2014;262 Pt A:66-71.

6. Elgart A, Zur AA, Mimrod D, et al. The effect of laquinimod, a novel immunomodulator in development to treat Huntington disease, on the pharmacokinetics of ethinylestradiol and levonorgestrel in healthy young women. Eur J Clin Pharmacol 2018.

7. Kaye J, Piryatinsky V, Birnberg T, et al. Laquinimod arrests experimental autoimmune encephalomyelitis by activating the aryl hydrocarbon receptor. Proceedings of the National Academy of Sciences of the United States of America 2016;113:E6145-E6152.

8. Bruck W, Pfortner R, Pham T, et al. Reduced astrocytic NF-kappaB activation by laquinimod protects from cuprizone-induced demyelination. Acta Neuropathol 2012;124:411-424.

9. Aharoni R, Saada R, Eilam R, Hayardeny L, Sela M, Arnon R. Oral treatment with laquinimod augments regulatory $\mathrm{T}$-cells and brain-derived neurotrophic factor expression and reduces injury in the CNS of mice with experimental autoimmune encephalomyelitis. JNeuroimmunol 2012;251:14-24. 
10. Thone J, Ellrichmann G, Seubert S, et al. Modulation of autoimmune demyelination by laquinimod via induction of brain-derived neurotrophic factor. Am J Pathol 2012;180:267-274.

11. Comi G, Jeffery D, Kappos $L$, et al. Placebo-controlled trial of oral laquinimod for multiple sclerosis. N Engl J Med 2012;366:1000-1009.

12. Vollmer TL, Sorensen PS, Selmaj K, et al. A randomized placebo-controlled phase III trial of oral laquinimod for multiple sclerosis. J Neurol 2014;261:773-783.

13. Filippi M, Rocca MA, Pagani E, et al. Placebo-controlled trial of oral laquinimod in multiple sclerosis: MRI evidence of an effect on brain tissue damage. $J$ Neurol Neurosurg Psychiatry 2013;85:851-858.

14. Kurtzke JF. Rating neurologic impairment in multiple sclerosis: an expanded disability status scale (EDSS). Neurology 1983;33:1444-1452.

15. Daams M, Weiler F, Steenwijk MD, et al. Mean upper cervical cord area (MUCCA) measurement in long-standing multiple sclerosis: relation to brain findings and clinical disability. Mult Scler 2014;20:1860-1865.

16. MIPAV (Medical Image Processing, Analysis, and Visualization) [online]. Available at: https://mipav.cit.nih.gov/.

17. Jain S, Sima DM, Ribbens A, et al. Automatic segmentation and volumetry of multiple sclerosis brain lesions from MR images. Neuroimage Clin 2015;8:367-375.

18. Patenaude B, Smith SM, Kennedy DN, Jenkinson M. A Bayesian model of shape and appearance for subcortical brain segmentation. Neuroimage 2011;56:907-922.

19. Comi G, Vollmer T, Boyko A, et al. CONCERTO: a placebo-controlled trial of oral laquinimod in patients with relapsing-remitting multiple sclerosis. Multiple sclerosis journal, 2017: 74-75.

20. Lublin F, Miller DH, Freedman MS, et al. Oral fingolimod in primary progressive multiple sclerosis (INFORMS): a phase 3, randomised, double-blind, placebo-controlled trial. Lancet 2016;387:1075-1084. 
21. Kappos L, Radue EW, O'Connor P, et al. A placebo-controlled trial of oral fingolimod in relapsing multiple sclerosis. N Engl J Med 2010;362:387-401.

22. Fox RJ, Coffey CS, Conwit R, et al. Phase 2 Trial of lbudilast in Progressive Multiple Sclerosis. N Engl J Med 2018;379:846-855.

23. Miller DH, Leary SM. Primary-progressive multiple sclerosis. The Lancet Neurology 2007;6:903-912.

24. Tourbah A, Lebrun-Frenay C, Edan G, et al. MD1003 (high-dose biotin) for the treatment of progressive multiple sclerosis: A randomised, double-blind, placebocontrolled study. Mult Scler 2016;22:1719-1731.

25. Arnold DL. MD1003 in progressive multiple sclerosis: 24-month brain MRI results of the MS-SPI trial. In: library EO, ed.2017.

26. Chataway J, Schuerer N, Alsanousi A, et al. Effect of high-dose simvastatin on brain atrophy and disability in secondary progressive multiple sclerosis (MSSTAT): a randomised, placebo-controlled, phase 2 trial. Lancet 2014;383:2213-2221.

27. Montalban X, Belachew S, Wolinsky JS. Ocrelizumab in Primary Progressive and Relapsing Multiple Sclerosis. N Engl J Med 2017;376:1694.

28. Wolinsky JS, Narayana PA, O'Connor P, et al. Glatiramer acetate in primary progressive multiple sclerosis: results of a multinational, multicenter, double-blind, placebo-controlled trial. Ann Neurol 2007;61:14-24.

29. Hawker K, O'Connor P, Freedman MS, et al. Rituximab in patients with primary progressive multiple sclerosis: results of a randomized double-blind placebocontrolled multicenter trial. Ann Neurol 2009;66:460-471. 


\section{FIGURE LEGENDS}

Figure 1. Percent brain volume change. Adjusted mean PBVC from baseline to 48 weeks for laquinimod $0.6 \mathrm{mg}$ and placebo arms (primary endpoint). Only on-treatment observations were included. $\mathrm{Cl}=$ confidence interval; $\mathrm{mITT}=$ modified intent to treat PBVC = percentage brain volume change; SE = standard error.

Figure 2. Disease progression confirmed after 12 weeks. Shown are the Kaplan-Meier estimates for the risk of disease progression confirmed after at least 12 weeks (first secondary endpoint) for the laquinimod $0.6 \mathrm{mg}$ and placebo arms during the nearly 30 month study. Only on-treatment observations were included. CDP = confirmed disability progression; EDSS = Expanded Disability Status Scale; ITT = intent to treat. 


\section{TABLES}

Table 1. Demographics and baseline characteristics for the ITT population

\begin{tabular}{|c|c|c|c|c|}
\hline Demographic variables & $\begin{array}{l}\text { Placebo } \\
(n=140)\end{array}$ & $\begin{array}{l}\text { Laquinimod } 0.6 \mathrm{mg} \\
\qquad(\mathrm{n}=139)\end{array}$ & $\begin{array}{l}\text { Laquinimod } 1.5 \mathrm{mg} \\
\qquad(\mathrm{n}=95)\end{array}$ & $\begin{array}{c}\text { Total } \\
(n=374)\end{array}$ \\
\hline \multicolumn{5}{|l|}{ Age, years } \\
\hline Mean (SD) & $46.6(7.2)$ & $46.1(6.7)$ & $46.1(7.2)$ & $46.3(7.0)$ \\
\hline Median & 49.0 & 47.0 & 48.0 & 48.0 \\
\hline Min, $\max$ & 26,56 & 25,55 & 25,55 & 25,56 \\
\hline Male, n (\%) & $73(52)$ & $82(59)$ & $50(53)$ & $205(55)$ \\
\hline \multicolumn{5}{|l|}{ Race, n (\%) } \\
\hline White & $138(99)$ & $132(95)$ & $92(97)$ & $362(97)$ \\
\hline Black & 0 & $2(1)$ & $2(2)$ & $4(1)$ \\
\hline Asian & 0 & $2(1)$ & 0 & $2(<1)$ \\
\hline Other & $2(1)$ & $3(2)$ & $1(1)$ & $6(2)$ \\
\hline \multicolumn{5}{|l|}{ BMI, $\mathrm{kg} / \mathrm{m}^{2}$} \\
\hline Mean (SD) & $25.1(5.0)$ & $25.4(4.6)$ & $25.0(4.1)$ & $25.2(4.6)$ \\
\hline Median & 24.1 & 25.1 & 24.9 & 24.7 \\
\hline Min, max & $14.9,44.9$ & $17.5,43.3$ & $17.0,40.4$ & $14.9,44.9$ \\
\hline \multicolumn{5}{|l|}{ Baseline EDSS score } \\
\hline Mean (SD) & $4.5(0.9)$ & $4.5(1.0)$ & $4.4(1.0)$ & $4.5(0.9)$ \\
\hline Median & 4.5 & 4.5 & 4.0 & 4.5 \\
\hline Min, $\max$ & $3.0,6.5$ & $3.0,6.5$ & $3.0,6.5$ & $3.0,6.5$ \\
\hline \multicolumn{5}{|c|}{ Time since symptom onset (years) } \\
\hline $\mathrm{n}$ & 140 & 139 & 94 & 373 \\
\hline Mean (SD) & $7.4(5.2)$ & $8.3(6.3)$ & $8.5(5.6)$ & $8.0(5.8)$ \\
\hline Median & 6.5 & 6.6 & 7.1 & 6.7 \\
\hline Min, $\max$ & 1,38 & 1,36 & 2,29 & 1,38 \\
\hline \multicolumn{5}{|c|}{ Time since diagnosis (years) } \\
\hline Mean (SD) & $3.1(3.0)$ & $4.0(4.1)$ & $4.1(4.0)$ & $3.7(3.7)$ \\
\hline Median & 2.2 & 2.5 & 2.9 & 2.5 \\
\hline Min, $\max$ & 0,17 & 0,25 & 0,19 & 0,25 \\
\hline
\end{tabular}


Prior use of DMT, $n$

(\%)

$\geq 1$ GdE-T1 lesions

at baseline, $\mathrm{n}$ (\%)

Normalized brain volume $(\mathrm{ml})$

$\begin{array}{lc}\text { Mean (SD) } & 1457.9(109.8) \\ \text { Min, max } & 1204,1852\end{array}$

Timed 25-foot walk (second)

n 140

Mean (SD)

$9.7(7.4)$

Min, max

$3.2,46.0$

Number of T1 enhancing lesions

Mean (SD)

140

Min, max

$0.4(1.8)$

0,18

T2 lesion volume (ml)

n 140

Mean (SD)

$5.9(8.7)$

Min, max

$0,62.7$

Number of T2 cervical cord lesions

$\mathrm{n}$ 134

Mean (SD)

$3.0(2.0)$

Min, max

0,10

Upper cervical cord area $\left(\mathrm{mm}^{2}\right)$

n

Mean (SD)

$72.8(9.4)$

Min, max

$43.7,96.7$

MTR normal-appearing brain tissue (\%)

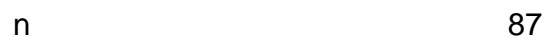

Mean (SD)

$35.6(4.6)$

Min, max

$25.0,46.8$

Normalized thalamic volume $(\mu \mathrm{l})$
128

$3.1(2.1)$

0,10

137

$74.0(10.4)$

43.5, 101.9

82

$35.0(4.6)$

$25.2,46.4$
92

$2.8(2.1)$

0,11

92

$73.2(10.1)$

$54.4,99.2$

52

35.3 (4.3)

$35.3(4.5)$

$26.2,44.3$

$25.0,46.8$
221

354

$3.0(2.0)$

0,11

368

73.4 (9.9)

$43.5,101.9$ $\mathrm{n}$

139
137

95 


$\begin{array}{lrccc}\text { Mean }(\mathrm{SD}) & 18783.3(2322.5) & 18671.3(2111.8) & 18826.1(2163.3) & 18752.9(2200.9) \\ \text { Min, } \max & 12757,24488 & 11524,23457 & 13077,24738 & 11524,24738\end{array}$

\section{Normalized cortical grey matter volume (ml)}

n

136

136

92

364

Mean (SD)

$849.3(44.9)$

$842.7(44.0)$

$842.4(43.8)$

$845.1(44.3)$

Min, max

674,971

730,986

712,929

674,986

Normalized white matter volume $(\mathrm{ml})$

$\mathrm{n}$

140

139

93

372

Mean (SD)

$720.5(82.2)$

$730.9(79.1)$

$724.9(77.1)$

725.5 (79.7)

Min, $\max$

568,1089

598, 964

562,1033

562, 1089

Low-contrast visual acuity score (chart type 100\%)

n

130

129

88

347

Mean (SD)

$51.6(8.8)$

$51.4(10.5)$

$50.1(10.6)$

$51.2(9.9)$

Min, max

20,69

16,70

9,70

9,70

T1 hypointense lesion volume $(\mathrm{mL})$

n 140

138

95

373

Mean (SD)

$1.7(3.0)$

$2.3(4.3)$

$2.6(4.2)$

$2.2(3.8)$

Min, $\max$

$(0,17.1)$

$0,22.1$

$0,22.3$

$0,22.3$

Number of T1 hypointense lesion

N/A

Number of T2 lesions

N/A

Abbreviations: $\mathrm{BMI}=$ body mass index; $\mathrm{DMT}=$ disease-modifying treatment; $\mathrm{EDSS}=$ Expanded Disability Status Scale; GdE = gadolinium enhancing; ITT = intention-to-treat; $\max =$ maximum; $\min =$ minimum; MTR = magnetization transfer ratio; $N / A=$ not available; $S D=$ standard deviation. Analysis was completed in the ITT population, which consisted of all randomized patients.

The numbers of T2 lesions and T1 hypointense lesions were not collected at baseline. 
Table 2. Secondary and exploratory efficacy endpoints: change from baseline to Week 48

\begin{tabular}{|c|c|c|c|c|c|c|c|c|c|}
\hline \multirow[b]{3}{*}{ Efficacy measure } & \multicolumn{2}{|c|}{$\begin{array}{l}\text { Laquinimod } 0.6 \mathrm{mg} \\
\qquad(\mathrm{n}=139)\end{array}$} & \multicolumn{2}{|c|}{$\begin{array}{l}\text { Placebo } \\
(n=140)\end{array}$} & \multicolumn{5}{|c|}{$\begin{array}{l}\text { Laquinimod } 0.6 \mathrm{mg} \text { vs placebo } \\
\qquad \mathrm{N}=279\end{array}$} \\
\hline & \multicolumn{4}{|c|}{ Endpoint values } & \multicolumn{5}{|c|}{ Treatment effects } \\
\hline & $\mathbf{n}$ & Measure & $\mathbf{n}$ & Measure & $\mathbf{n}$ & Estimate & SE & $95 \% \mathrm{Cl}$ & $p$ value \\
\hline CDP (EDSS), n (\%) ${ }^{a}$ & 139 & $24(17)$ & 140 & $32(23)$ & 279 & $0.8^{b}$ & NA & 0.48 to 1.37 & 0.426 \\
\hline CDP (EDSS or T25FW), $\mathrm{n}(\%)^{\mathrm{a}}$ & 139 & $44(32)$ & 140 & $47(34)$ & 276 & $1.0^{\mathrm{b}}$ & NA & 0.68 to 1.59 & 0.867 \\
\hline Change in median T25FW score (seconds) ${ }^{c}$ & 108 & 0.05 & 121 & 0.30 & 229 & -0.325 & 0.2679 & -0.8500 to 0.2000 & 0.248 \\
\hline New T2 lesions, adjusted mean $(95 \% \mathrm{CI})^{d}$ & 111 & $0.7^{e}$ & 119 & $1.6^{f}$ & 230 & $0.4 \mathrm{~g}$ & 0.11 & 0.26 to 0.69 & 0.001 \\
\hline T1 lesion volume change $(\mathrm{ml})^{d}$ & 109 & 0.0 & 115 & 0.0 & 224 & 0.0 & 0.0 & 0.0 to 0.0 & 0.040 \\
\hline T2 lesion volume change $(\mathrm{ml})^{\mathrm{d}}$ & 112 & 0 & 119 & 3 & 231 & -10.0 & 5.1 & -20.00 to 0.00 & 0.014 \\
\hline T2 cervical cord lesions ${ }^{d}$ & 98 & 2.9 & 106 & 3 & 204 & 1 & 0.1 & 0.79 to 1.18 & 0.729 \\
\hline Upper cervical cord area $\left(\mathrm{cm}^{3}\right)^{d}$ & 103 & -1.54 & 97 & -0.87 & 200 & -0.673 & 0.498 & -1.6558 to 0.3091 & 0.178 \\
\hline MTR normal-appearing brain tissue ${ }^{d}$ & 60 & 0.3 & 69 & 0.05 & 129 & 0.235 & 0.1791 & -0.1194 to 0.5899 & 0.192 \\
\hline Thalamic volume $(\mathrm{ml})^{\mathrm{d}}$ & 93 & -0.740 & 98 & -0.986 & 191 & 0.245 & 0.426 & -0.5952 to 1.0859 & 0.565 \\
\hline Cortical grey matter volume $(\mathrm{ml})^{d}$ & 98 & -0.342 & 113 & -0.470 & 211 & 0.129 & 0.1455 & -0.1583 to 0.4154 & 0.378 \\
\hline White matter volume $(\mathrm{ml})^{\mathrm{d}}$ & 101 & -0.872 & 97 & -0.775 & 198 & -0.097 & 0.3993 & -0.8848 to 0.6908 & 0.808 \\
\hline New T1 hypointense lesions ${ }^{d}$ & 108 & 0.4 & 115 & 0.7 & 223 & $0.5^{g}$ & 0.18 & 0.27 to 1.01 & 0.055 \\
\hline Low-contrast letter acuity score (chart type & 105 & 0.991 & 113 & 0.206 & 218 & 0.785 & 0.7708 & -0.7295 to 2.3002 & 0.309 \\
\hline $100 \%)^{c}$ & & & & & & & & & \\
\hline
\end{tabular}


Abbreviations: 9HPT = 9-Hole Peg Test; BVMT = Brief Visuospatial Memory Test; CDP = confirmed disability progression; $\mathrm{Cl}=$ confidence interval; CVLT = California Verbal Learning Test; EDSS = Expanded Disability Status Scale; ITT = intention-to-treat; LCVA = low-contrast visual acuity; mITT = modified intention-to-treat; MSWS-12 = 12-Item Multiple Sclerosis Walking Scale; MTR = magnetization transfer ratio; NA = not applicable; SDMT = Symbol Digit Modalities Test; SE = standard error; T25FW = timed 25-foot walk.

Patients with insufficient MRI scan quality and/or no valid baseline values were excluded from efficacy analyses.

a Analysis was completed in the ITT population, which consisted of all randomized patients.

b Hazard ratio.

${ }^{c}$ Analysis was completed in the mITT2 population, which consisted of all randomized patients with at least 1 post-baseline assessment (EDSS, SDMT, CVLT, BVMT, T25FW, 9HPT, LCVA and/or MSWS-12).

${ }^{d}$ Analysis was completed in the mITT1 population, which consisted of all randomized patients with at least 1 post-baseline PBVC assessment.

e $95 \% \mathrm{Cl}: 0.44$ to 0.98 .

f $95 \% \mathrm{Cl}: 1.13$ to 2.16 .

${ }^{g}$ Risk ratio. 


\section{Table 3. Safety summary (safety population)}

\begin{tabular}{|c|c|c|c|c|c|c|}
\hline & \multicolumn{2}{|c|}{$\begin{array}{c}\text { Placebo } \\
(n=140, P Y=225.9)\end{array}$} & \multicolumn{2}{|c|}{$\begin{array}{l}\text { Laquinimod } 0.6 \mathrm{mg} \\
(\mathrm{n}=138, \mathrm{PY}=203.3 \text { ) }\end{array}$} & \multicolumn{2}{|c|}{$\begin{array}{l}\text { Laquinimod } 1.5 \mathrm{mg} \\
(\mathrm{n}=95, \mathrm{PY}=28.7)\end{array}$} \\
\hline & n (\%) & Event rate per 100 years & n (\%) & Event rate per 100 years & n (\%) & Event rate per 100 years \\
\hline Patients $\geq 1 \mathrm{AE}$ & $109(78)$ & 215.1 & $115(83)$ & 266.6 & $63(66)$ & 665.5 \\
\hline Patients $\geq 1$ SAE & $6(4)$ & 4.0 & $10(7)$ & 6.4 & $3(3)$ & 13.9 \\
\hline Patients $\geq 1 \mathrm{AE}$ leading to & $2(1)$ & 0.89 & $8(6)$ & 3.94 & $4(4)$ & 17.42 \\
\hline \multicolumn{7}{|l|}{ discontinuation } \\
\hline Deaths* & 0 & 0 & 0 & 0 & $1(1)$ & 3.48 \\
\hline
\end{tabular}

Abbreviations: $\mathrm{AE}=$ adverse event; $\mathrm{SAE}=$ serious adverse event; $\mathrm{PY}=$ patient-years.

*One death occurred during screening, and 1 death occurred in the $1.5 \mathrm{mg}$ dose arm 35 days after the last dose of laquinimod during safety follow-up. 
Table 4. Most common adverse events(>5\%) occurring in the safety population

\begin{tabular}{|c|c|c|c|}
\hline Preferred term & $\begin{array}{c}\text { Placebo } \\
(n=140, P Y=225.9)\end{array}$ & $\begin{array}{l}\text { Laquinimod } 0.6 \mathrm{mg} \\
(\mathrm{n}=138, \mathrm{PY}=203.3 \text { ) }\end{array}$ & $\begin{array}{l}\text { Laquinimod } 1.5 \mathrm{mg} \\
(\mathrm{n}=95, \mathrm{PY}=28.7)\end{array}$ \\
\hline Nasopharyngitis & $24(17 \%)$ & $24(17 \%)$ & $4(4 \%)$ \\
\hline Headache & $16(11 \%)$ & $14(10 \%)$ & $15(16 \%)$ \\
\hline Back pain & $15(11 \%)$ & $12(9 \%)$ & $5(5 \%)$ \\
\hline Influenza & $13(9 \%)$ & $7(5 \%)$ & $2(2 \%)$ \\
\hline Upper respiratory tract infection & $6(4 \%)$ & $12(9 \%)$ & $2(2 \%)$ \\
\hline Urinary tract infection & $11(8 \%)$ & $9(7 \%)$ & $4(4 \%)$ \\
\hline Pain in extremity & $8(6 \%)$ & $6(4 \%)$ & $1(1 \%)$ \\
\hline Fall & $9(6 \%)$ & $9(7 \%)$ & $4(4 \%)$ \\
\hline Diarrhea & $6(4 \%)$ & $9(7 \%)$ & $1(1 \%)$ \\
\hline Arthralgia & $6(4 \%)$ & $8(6 \%)$ & $6(6 \%)$ \\
\hline Nausea & $3(2 \%)$ & $4(3 \%)$ & $6(6 \%)$ \\
\hline Abdominal pain upper & $2(1 \%)$ & $4(3 \%)$ & $6(6 \%)$ \\
\hline Fatigue & $6(4 \%)$ & $7(5 \%)$ & $3(3 \%)$ \\
\hline Constipation & $6(4 \%)$ & $7(5 \%)$ & $3(3 \%)$ \\
\hline
\end{tabular}

Abbreviation: $P Y=$ patient-years. 
Table 5. Serious adverse events (safety population)

\begin{tabular}{lccc}
\hline Preferred terms & Placebo & Laquinimod 0.6 mg & Laquinimod 1.5 mg \\
& $(n=140$, & $(n=138$, & $(n=95$, \\
& $P Y=225.9)$ & $P Y=203.3)$ & $P Y=28.7)$
\end{tabular}

Cardiac disorders, ${ }^{*}$ n (\%)

Acute myocardial infarction

$1(<1)$

0

0

Angina unstable

0

0

$1(1)$

General disorders and administration site conditions, $\mathbf{n}(\%)$

$\begin{array}{lccc}\text { Influenza-like illness } & 1(<1) & 0 & 0 \\ \text { Edema peripheral } & 0 & 1(<1) & 0\end{array}$

Infections and infestations, $\mathbf{n}(\%)$

$\begin{array}{lccc}\text { Urinary tract infection } & 2(1) & 1(<1) & 0 \\ \text { Bacterial pyelonephritis } & 0 & 1(<1) & 0 \\ \text { Pneumonia } & 0 & 1(<1) & 0 \\ \text { Testicular abscess } & 0 & 0 & 1(1) \\ \text { Urosepsis } & 0 & 1(<1) & 0\end{array}$

Investigations

HIV positive

0

$1(<1)$

0

Metabolism and nutritional disorders, $\mathbf{n}(\%)$

Hypokalemia

$1(<1)$

0

0

Musculoskeletal and connective tissue disorders, $\mathbf{n}(\%)$
Intervertebral disc disorder
$1(<1)$
0
0
Muscle spasms
0
$1(<1)$
0

Nervous system disorders, $n$ (\%)

$\begin{array}{lccc}\text { Multiple sclerosis relapse } & 1(<1) & 1(<1) & 0 \\ \text { Dizziness } & 0 & 1(<1) & 0 \\ \text { Facial paralysis } & 0 & 1(<1) & 0 \\ \text { Lumbosacral plexopathy } & 0 & 0 & 1(1) \\ \text { Neuromyelitis optica spectrum } & 0 & 0 & 1(1) \\ \text { disorder } & & & \end{array}$

Renal and urinary disorders, $\mathrm{n}(\%)$

Acute kidney failure

$1(<1)$

0

0

Urinary retention

0

$1(<1)$

0 
Abbreviations: $\mathrm{PY}=$ patient-years; $\mathrm{SAE}=$ serious adverse event.

${ }^{*}$ An additional fatal SAE of myocardial ischemia occurred after exposure to laquinimod $1.5 \mathrm{mg}$. The SAE (described in the safety and tolerability section) was reported as "atherosclerotic coronary artery disease" but is not listed in this table, because the event occurred after study drug discontinuation.

Figure 1. Percent brain volume change (mITT1 population). Adjusted mean PBVC from baseline to 48 weeks for laquinimod $0.6 \mathrm{mg}$ and placebo arms (primary endpoint). Only ontreatment observations were included. $\mathrm{mITT}=$ modified intent to treat; $\mathrm{PBVC}=$ percentage brain volume change; SE = standard error.

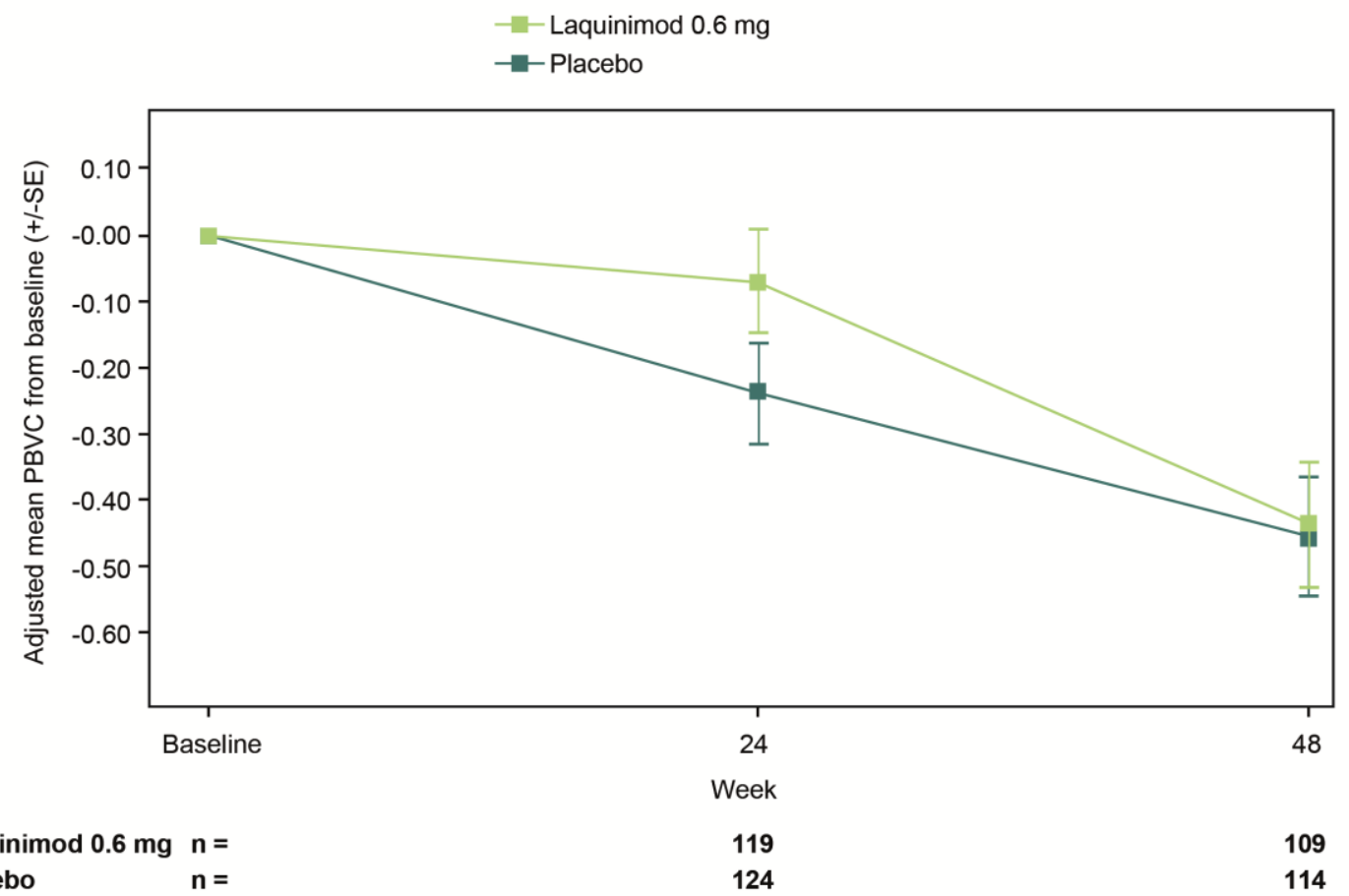

Analysis was completed for the mITT1 population, which consisted of all randomized patients with at least 1 post-baseline PBVC assessment. 
Figure 2. Disease progression confirmed after 12 weeks (ITT population). Shown are the Kaplan-Meier estimates for the risk of disease progression confirmed after at least 12 weeks (first secondary endpoint) for the laquinimod $0.6 \mathrm{mg}$ and placebo arms during the nearly 30-month study. Only on-treatment observations were included. CDP $=$ confirmed disability progression; EDSS = Expanded Disability Status Scale; ITT = intent to treat.

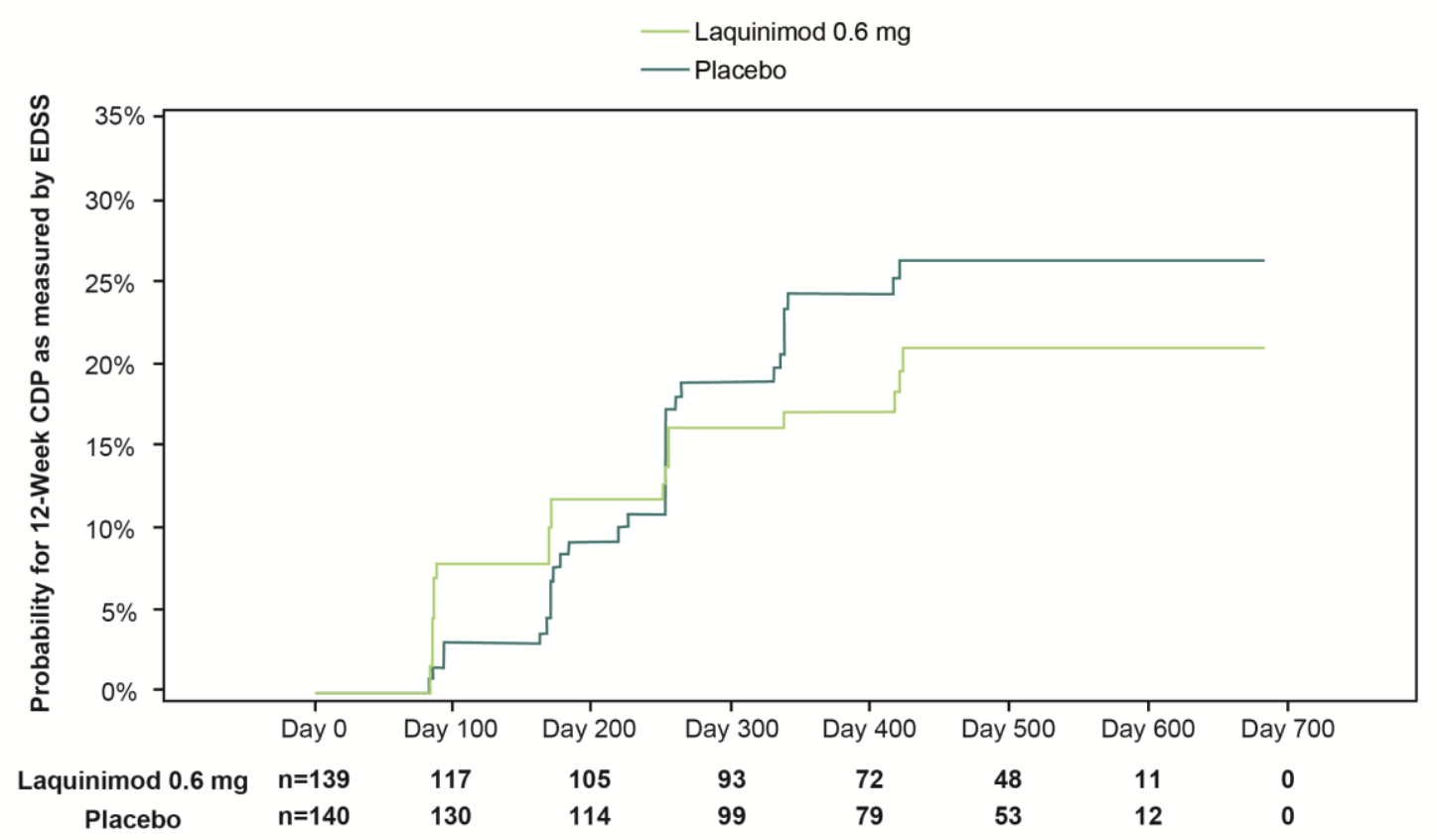

The ITT population consisted of all randomized patients. 


\section{SUPPLEMENTAL DATA}

\section{SUPPLEMENTAL TABLES}

\section{Table e-1. Exploratory endpoints at Week 48}

\begin{tabular}{|c|c|c|c|c|c|c|}
\hline Laquinimod $0.6 \mathrm{mg}$ vs. placebo & $\mathbf{N}$ & Output & Estimate & Standard error & $95 \% \mathrm{Cl}$ & $P$ value \\
\hline \multicolumn{7}{|l|}{ BICAMS, adjusted mean $(95 \% \mathrm{Cl})$} \\
\hline CVLT-II - Verbal memory & 224 & Treatment effect & 0.340 & 1.0323 & $-1.6945,2.3750$ & 0.742 \\
\hline BVMT - Nonverbal memory & 199 & Treatment effect & 0.382 & 0.7957 & $-1.1876,1.9510$ & 0.632 \\
\hline SDMT - Processing speed & 232 & Treatment effect & 1.987 & 0.9716 & $0.0812,3.8934$ & 0.41 \\
\hline MSWS-12 & 232 & Treatment effect & -2.045 & 1.1972 & $-4.3936,0.3036$ & 0.088 \\
\hline 9HPT & 235 & Treatment effect & -0.525 & 0.5102 & $-1.5250,0.4750$ & 0.412 \\
\hline \multicolumn{7}{|l|}{ CDP alternatives, $\mathrm{n}(\%)$} \\
\hline 12-week EDSS CDP & 276 & Hazard ratio & 0.9 & & $0.52,1.41$ & 0.541 \\
\hline 12-week CDP (EDSS, T25FW, 9HPT, or SDMT) & 276 & Hazard ratio & 1.0 & & $0.68,1.45$ & 0.989 \\
\hline
\end{tabular}


Abbreviations: 9HPT = 9-Hole Peg test; BICAMS = Brief International Cognitive Assessment for Multiple Sclerosis; BVMT = Brief Visuospatial Memory Test; $\mathrm{CDP}=$ confirmed disability progression; $\mathrm{Cl}$ = confidence interval; CVLT-II = California Verbal Learning Test-II; EDSS = Expanded Disability Status Scale; $\mathrm{N}=$ number of patients included in the analysis; LCVA = low-contrast visual acuity; MSWS-12 = 12-Item Multiple Sclerosis Walking Scale; SDMT = Symbol Digit Modalities Test; T25FW = timed 25-foot walk.

a Estimated mean. 
Table e-2. Patients with prior use of MS disease-modifying treatment (ITT population)

\begin{tabular}{|c|c|c|c|c|}
\hline & $\begin{array}{l}\text { Placebo } \\
(n=140)\end{array}$ & $\begin{array}{l}\text { Laquinimod } 0.6 \mathrm{mg} \\
\qquad(\mathrm{n}=139)\end{array}$ & $\begin{array}{l}\text { Laquinimod } 1.5 \mathrm{mg} \\
\qquad(\mathrm{n}=95)\end{array}$ & $\begin{array}{c}\text { Total } \\
(\mathrm{n}=374)\end{array}$ \\
\hline Patients with prior DMT use, $\mathrm{n}(\%)$ & $31(22)$ & $28(20)$ & $30(32)$ & $89(24)$ \\
\hline Investigational drug & $4(3)$ & $10(7)$ & $12(13)$ & $26(7)$ \\
\hline Antineoplastic agents & 0 & $1(<1)$ & $2(2)$ & $3(<1)$ \\
\hline Mitoxantrone & 0 & 0 & $2(2)$ & $2(<1)$ \\
\hline Rituximab & 0 & $1(<1)$ & 0 & $1(<1)$ \\
\hline Corticosteroids for systemic use & $1(<1)$ & 0 & 0 & $1(<1)$ \\
\hline Methylprednisolone & $1(<1)$ & 0 & 0 & $1(<1)$ \\
\hline Immune sera and immunoglobulins & 0 & $1(<1)$ & $1(1)$ & $2(<1)$ \\
\hline Immunoglobulins NOS & 0 & $1(<1)$ & $1(1)$ & $2(<1)$ \\
\hline Immunostimulants & $17(12)$ & $10(7)$ & $12(13)$ & $39(10)$ \\
\hline Glatiramer acetate & $8(6)$ & $3(2)$ & $7(7)$ & $18(5)$ \\
\hline Interferon beta- $1 \mathrm{a}$ & $8(6)$ & $6(4)$ & $3(3)$ & $17(5)$ \\
\hline Interferon beta- $1 \mathrm{~b}$ & $5(4)$ & $2(1)$ & $2(2)$ & $9(2)$ \\
\hline Interferon beta & 0 & 0 & $1(1)$ & $1(<1)$ \\
\hline Immunosuppressants & $8(6)$ & $10(7)$ & $13(14)$ & $31(8)$ \\
\hline Fingolimod & $3(2)$ & $5(4)$ & $10(11)$ & $18(5)$ \\
\hline Azathioprine & $1(<1)$ & $2(1)$ & $2(2)$ & $5(1)$ \\
\hline Fingolimod hydrochloride & $3(2)$ & $1(<1)$ & $1(1)$ & $5(1)$ \\
\hline Methotrexate & $1(<1)$ & 0 & 0 & $1(<1)$ \\
\hline Methotrexate sodium & 0 & $1(<1)$ & 0 & $1(<1)$ \\
\hline
\end{tabular}




\begin{tabular}{|c|c|c|c|c|}
\hline & $\begin{array}{l}\text { Placebo } \\
(n=140)\end{array}$ & $\begin{array}{l}\text { Laquinimod } 0.6 \mathrm{mg} \\
\qquad(\mathrm{n}=139)\end{array}$ & $\begin{array}{l}\text { Laquinimod } 1.5 \mathrm{mg} \\
\qquad(\mathrm{n}=95)\end{array}$ & $\begin{array}{c}\text { Total } \\
(n=374)\end{array}$ \\
\hline Ocrelizumab & 0 & $1(<1)$ & 0 & $1(<1)$ \\
\hline Teriflunomide & $1(<1)$ & 0 & 0 & $1(<1)$ \\
\hline Muscle relaxants & $1(<1)$ & 0 & 0 & $1(<1)$ \\
\hline Baclofen & $1(<1)$ & 0 & 0 & $1(<1)$ \\
\hline Tizanidine hydrochloride & $1(<1)$ & 0 & 0 & $1(<1)$ \\
\hline Other nervous system drugs & $2(1)$ & $4(3)$ & $2(2)$ & $8(2)$ \\
\hline Fampridine & $2(1)$ & $4(3)$ & 0 & $6(2)$ \\
\hline Dimethyl fumarate & 0 & 0 & $2(2)$ & $2(<1)$ \\
\hline Unspecified herbal and traditional medicine & $1(<1)$ & 0 & 0 & $1(<1)$ \\
\hline Camellia sinensis & $1(<1)$ & 0 & 0 & $1(<1)$ \\
\hline Urologicals & $1(<1)$ & 0 & 0 & $1(<1)$ \\
\hline Fesoterodine fumarate & $1(<1)$ & 0 & 0 & $1(<1)$ \\
\hline Uncoded & $4(3)$ & $1(<1)$ & $1(1)$ & $6(2)$ \\
\hline Blood and blood-forming organs & $4(3)$ & $1(<1)$ & $1(1)$ & $6(2)$ \\
\hline
\end{tabular}

Abbreviations: DMT = disease-modifying treatment; ITT = intention-to-treat; MS = multiple sclerosis; NOS = not otherwise specified. 
Table e-3. Trial comparison

\begin{tabular}{|c|c|c|c|c|c|c|}
\hline & INFORMS ${ }^{17}$ & ORATORIO'19, 26 & PROMISE $^{27}$ & OLYMPUS $^{21}$ & SPRINT 22 & ARPEGGIO \\
\hline \multicolumn{7}{|l|}{ Study characteristics } \\
\hline Study drug & Fingolimod & Ocrelizumab & Glatiramer acetate & Rituximab & Ibudilast & Laquinimod \\
\hline Study period & 36 months & 120 weeks & 36 months & 96 weeks & 96 weeks & 48 weeks \\
\hline $\mathrm{N}$ & 823 & 732 & 943 & 439 & 255 & 374 \\
\hline \multicolumn{7}{|l|}{ Baseline characteristics } \\
\hline Age, mean years (SD) & $48.5(8.4)$ & 44.6 & $50.4(8.3)$ & $49.9(8.9)$ & 56 & $46.3(7.0)$ \\
\hline Male, n (\%) & $425(52)$ & $371(50.7)$ & $460(48.8)$ & $218(49.7)$ & $133(66.5)$ & $205(55.0)$ \\
\hline White, n (\%) & $791(96)$ & 94.1 & $747(89.8)$ & $402(91.6)$ & $236(92.5)$ & $362(97)$ \\
\hline $\begin{array}{l}\text { Time since symptom } \\
\text { onset, mean years (SD) }\end{array}$ & $5.8(2.4)$ & $6.5(3.89)$ & $10.9(7.5)$ & $9.1(6.6)$ & $\begin{array}{c}\text { Median } 9 \text { years } \\
\text { placebo, } 11 \text { years }\end{array}$ & $8.0(5.8)$ \\
\hline & & & & & treatment arm & \\
\hline EDSS score, mean (SD) & $4.67(1.03)$ & $4.70(1.7)$ & $4.9(1.2)$ & $4.8(1.4)$ & $\begin{array}{c}\text { Median } 6 \text { both } \\
\text { arms }\end{array}$ & $4.5(0.9)$ \\
\hline Prior use of DMT, n (\%) & $179(22)$ & $85(12.0)$ & NR & $154(35.1)$ & NR & $89(24)$ \\
\hline \multicolumn{7}{|c|}{ Study endpoint baseline values } \\
\hline $\begin{array}{l}\text { T25FW score (seconds), } \\
\text { mean (SD) }\end{array}$ & $9.08(6.87)$ & NR & $12.4(13.8)$ & 8.08 median & $\begin{array}{c}\text { Median } 9.93 \\
\text { placebo, median }\end{array}$ & $9.7(8.4)$ \\
\hline
\end{tabular}




\begin{tabular}{|c|c|c|c|c|c|c|}
\hline & & & & & $\begin{array}{c}9.35 \text { treatment } \\
\text { arm }\end{array}$ & \\
\hline $\begin{array}{l}\text { 9-HPT dominant hand } \\
\text { score (s), mean (SD) }\end{array}$ & $28.65(14.62)$ & NR & $29.1(19.3)$ & NR & $\begin{array}{c}\text { Median } 30.31 \\
\text { placebo, median } \\
28.68 \text { treatment } \\
\text { arm }\end{array}$ & $32.4(22.4)$ \\
\hline $\begin{array}{l}\text { Gd-enhancing lesions } \\
\text { count, mean (SD) }\end{array}$ & $0.3(1.06)$ & $1.0(4.31)$ & $0.45(2.7)$ & NR & NR & $0.3(1.3)$ \\
\hline Free of $\mathrm{Gd}+, \mathrm{n}(\%)$ & $260(87.0)$ & $534(73.0)$ & 85.9 & 75.5 & NR & 84.2 \\
\hline $\begin{array}{l}\text { Total volume of T2 lesions } \\
\left(\mathrm{mm}^{3}\right) \text {, mean (SD) }\end{array}$ & $9794.5(11943.5)$ & 12,100 & NR & $\begin{array}{c}9173.3 \\
(13114.0)\end{array}$ & 10000 & $6129.0(8885.1)$ \\
\hline $\begin{array}{l}\text { Normalized brain volume } \\
\left(\mathrm{cm}^{3}\right) \text {, mean (SD) }\end{array}$ & $1491.4(85.5)$ & $1465.0(86.0)$ & NR & $\begin{array}{l}1205.8 \\
(123.3)\end{array}$ & $\mathrm{NR}$ & $1458.5(102.7)$ \\
\hline
\end{tabular}

Abbreviations: 9-HPT = 9-Hole Peg Test; DMT = disease-modifying treatment; EDSS = Expanded Disability Status Scale; Gd = gadolinium; NR = not reported; SD = standard deviation; T25FW = timed 25-foot walk. 